\title{
El naturalismo y el realismo de Marx
}

\author{
Christian Camilo Castaño García
}

Universidad Nacional de Colombia 


\section{El naturalismo y el realismo de Marx*}

Resumen: en el presente artículo se expone la concepción de la naturaleza en el pensamiento de Marx. Al respecto, se argumenta que Marx toma una posición naturalista y realista: naturalista, en cuanto considera que todo objeto natural es un objeto físico (es un objeto sensible); y realista porque considera que la realidad física existe independientemente de nuestras representaciones y del Absoluto hegeliano. Esto se expresa en la crítica de Marx al teísmo y al hegelianismo.

Palabras clave: Marx, ontología, naturalismo, realismo, Hegel, dialéctica.

\section{Marx's naturalism and realism}

Abstract: in this paper I pretend to expose the conception of nature in Marx's thought. In this sense, I argue that Marx takes a naturalistic and realistic stand: naturalistic insofar he considers that every natural object is a physical object (sensuous object); and realistic since he asserts that physical reality exists independently both of our representations and from Hegelian absolute. This is expressed in Marx criticism of theism and Hegelianism.

Keywords: Marx, ontology, naturalism, realism, Hegel, dialectics.

Fecha de recepción: 29 de mayo de 2019

Fecha de aceptación: 21 de agosto de 2019

Forma de citar (APA): Castaño-García, C. (2020). El naturalismo y el realismo de Marx. Revista Filosofía UIS, 19(2), https://doi.org/10.18273/revfil.v19n2-2020015

Forma de citar (Harvard): Castaño-García, C. (2020). El naturalismo y el realismo de Marx. Revista Filosofía UIS, 19(2), 285-313.

Christian Camilo Castaño García: colombiano. Magíster en Filosofía. Universidad Nacional de Colombia.

ORCID iD: orcid.org/0000-0003-1221-8130

Correo electrónico: cccastanog@unal.edu.co

"Artículo de reflexión derivado de investigación. 


\section{El naturalismo y el realismo de Marx}

\section{Naturalismo ontológico}

Hay dos variedades de naturalismo, el ontológico y el metodológico (Livingstone, 2017, pp. 161-162). El naturalismo ontológico da cuenta de aquello que existe o es el caso en la realidad, planteando que solo existen objetos y sucesos físicos. El naturalismo metodológico plantea que el mejor método para conocer la realidad es el método científico utilizado en las ciencias naturales. Este presupone un naturalismo ontológico, el cual no es muy controversial para la mayor parte de la comunidad científica y filosófica, aunque algunas de sus implicaciones no son compartidas por todos.

Una de las implicaciones de aceptar la tesis de que solo existen objetos y sucesos físicos, para Stroud (1996) es tener que descartar el sobrenaturalismo, esto es, desechar la perspectiva según la cual existen agentes que se sitúan por fuera del mundo natural y cuyas acciones no pueden comprenderse como parte de la naturaleza. Esto, por supuesto, no es aceptado por personas con creencias religiosas, ni por aquellos que niegan la posibilidad de una epistemología naturalista que pueda dar cuenta de cómo los seres humanos adquieren conocimiento del mundo natural en términos puramente biologicistas y evolutivos —el caso de Plantinga. Por otro lado, aceptar el naturalismo o una versión muy restrictiva de este, implica negar la posibilidad de algunos elementos de la vida humana como los estados intencionales en la percepción, la mente, la acción, etc.; o los juicios evaluativos en la medida en que se considere que todo lo que existe se agota con el conjunto de los hechos físicos, excluyendo con ello todo lo que no sea un hecho físico como algo que no puede ser verdadero o real.

En este artículo solo plantearemos la cuestión del naturalismo ontológico de Marx en relación a su concepción de la realidad física, no trataremos en cambio el naturalismo de Marx respecto a la realidad social ni de su naturalismo metodológico ${ }^{1}$. Hechas estas precisiones, pretendemos identificar y describir el

$\overline{1}$ Véase Little (1986). 
naturalismo de Marx en su concepción de la realidad física, i.e., de la naturaleza². Dicho esto, se argumentará que Marx tiene una concepción naturalista en la medida en que, por un lado, descarta el sobrenaturalismo en su crítica al teísmo, i.e., al creacionismo; y, por otra parte, en la medida que considera que la realidad física solo se compone de objetos físicos, esto es, objetos sensibles, entendiendo por estos aquellas entidades constituidas de materia que se ven afectadas por otros objetos o entidades, en últimas, aquellas que están sujetas a procesos causales. De esa manera, Marx considera que la naturaleza es un sistema de relaciones entre objetos sensibles que se ha autogenerado y constituido por procesos causales que no se deben a una agencia sobrenatural o a un principio racional estructurador (el absoluto o la Idea hegeliana).

\section{El naturalismo de Marx}

El naturalismo de Marx tiene su raíz en la filosofía de Feuerbach (1984), quien sitúa los hombres en la naturaleza y afirma que esta "es el fundamento del hombre". Con ello criticaba la noción que tenía Hegel de la naturaleza como manifestación del espíritu absoluto, con lo cual eliminaba su papel en relación con la autodeterminación de la conciencia (Díaz, 1986, p. 122). Así, Feuerbach considera el materialismo como el fundamento de la crítica a la religión y del idealismo objetivo de Hegel, al que consideraba como una rehabilitación de la teología. Apoyándose en ese materialismo funda una concepción de la naturaleza como algo real e independiente respecto de la conciencia, que tiene sus propias determinaciones y en la cual se encuentran inmersos los seres humanos. Por tal razón, Feuerbach (1984) enfatizaba que 'todas las ciencias tienen que fundarse en la naturaleza. Una teoría, mientras no haya encontrado su base natural, solo es una hipótesis'.

Marx se adhiere a las consideraciones de Feuerbach y fundaría en ellas buena parte de su postura filosófica respecto de la religión y la filosofía hegeliana, de esa forma aporta una nueva concepción del materialismo. En ese sentido, para Marx (2003) la única manera de entender la religión es considerando su origen en la enajenación económica de los hombres (p. 150). De igual forma, Marx interpreta la filosofía de Hegel como una restauración de la teología y la metafísica en una forma especulativa, esto también a través de la influencia de Feuerbach, quien consideraba que los atributos del Espíritu Absoluto eran aquellos atribuidos a Dios padre como sujeto creador omnipotente y omnipresente. Así, al igual que Feuerbach, Marx considerará la filosofía de Hegel como una inversión de

\footnotetext{
${ }^{2}$ Marx se ocupó del análisis de la realidad social y, en tanto materialista, su ontología social debe casar con su ontología general. Parto del supuesto de que Marx utiliza el término naturaleza para referirse con ello a lo que compone la denominada realidad física, i.e., aquella realidad compuesta de partículas organizadas en sistemas de materia inorgánica y materia orgánica. Con esto, en el concepto de naturaleza incluimos todo aquello que consideramos que está organizado en sistemas físicos, incluyendo lo que está en este planeta y fuera de él como parte del universo físico.
} 
la relación entre sujeto y predicado, en la que se predica al ser humano, la conciencia y la racionalidad, como atributo del Espíritu Absoluto en tanto que sujeto racional. Para Marx, en cambio, la realidad es otra, i.e., la conciencia y la racionalidad son atributos que se predican del hombre en tanto que sujeto corpóreo que hace parte del orden natural. En ese sentido, para él la filosofía hegeliana es una falsificación de la realidad, en la medida en que no parte de la naturaleza sino de una Idea abstracta que luego deviene naturaleza en el proceso de autoconstitución y realización del absoluto.

Con esos fundamentos y a través de la crítica a la filosofía especulativa de Hegel y de los neohegelianos, Marx partirá de una imagen de la naturaleza como algo increado e independiente de nuestras representaciones, fundamentando esta concepción en una crítica al teísmo, en la misma tradición del materialismo moderno; y en una crítica a la Filosofía de Hegel; con ello, Marx concluye que la realidad última es la naturaleza, que esta es previa a la conciencia o a cualquier principio del absoluto racional y que dicha naturaleza es de carácter procesual, de la cual surgen y están conformados los seres humanos.

\subsection{Crítica al teísmo}

Marx va concebir que la realidad se agota en el ámbito de la naturaleza, dentro de la cual se da el desarrollo de la realidad social como subsistema. En esa línea, concibe que la naturaleza es la única substancia, por ello negando la posibilidad del teísmo, esto es, la posibilidad de concebir la existencia de un dios creador que interviene en el universo desde fuera de sus límites. Esta perspectiva le viene del deísmo iluminista que predicaba Heinrich Marx, su padre, y del posterior estudio del sistema de Spinoza (Gonzáles, 2010, p. 15). Así, en el Cuaderno Spinoza, encontramos el siguiente extracto de Marx (2012) del Tratado Teológico-Político:

[6] Por ello, si ocurrió en la Naturaleza cualquier suceso que repugnase a sus leyes universales, repugnará necesariamente a la voluntad, al intelecto y a la naturaleza de Dios; o, si se afirmase que Dios obra contra alguna de las leyes de la Naturaleza, se debe al mismo tiempo afirmar que Dios actúa contra su propia naturaleza, lo que es una absurdidad sin igual (\#235). (p. 127)

Marx apunta esta conclusión de Spinoza, quien considera que los milagros no son intervenciones divinas de Dios sobre la naturaleza y a pesar de ella, sino muestra de la ignorancia de los individuos que desconocen las causas de algunos fenómenos físicos. Spinoza deriva esto de la conclusión de que las leyes naturales son decretos de Dios que se siguen de su propia esencia, por ende, tratando la naturaleza como la existencia misma de Dios, concibiendo que en la naturaleza no hay nada que no esté de acuerdo con su orden físico, que es de carácter 
necesario. De este fragmento, anotado por Marx en su lectura crítica de Spinoza, surge la cuestión de la relación de Dios con la naturaleza, esta última la cual crea y en la cual interviene, pero sin hacer parte él mismo del orden natural, dando lugar al siguiente dilema: (a) Dios hace parte del orden natural y está sujeto a las leyes de dicho orden, por ende, es real pero no es autosuficiente y omnipotente en tanto que sujeto a dichas leyes; o (b) Dios no hace parte del orden natural y no está sujeto a sus leyes, por ende, no es real, no creó la naturaleza y su autosuficiencia y omnipotencia son producto de la abstracción humana.

Marx (2003) va a tomar partido por (b), concibiendo que en el orden natural no hay nada que anteceda ni esté por encima de la naturaleza como su demiurgo ni creador. En ese sentido, Marx va a considerar que la naturaleza es un 'ser por sí mismo' que no depende de un "ser extraño por encima de la naturaleza y del hombre" (pp. 151-152). Por ello, escribe lo siguiente en los Manuscritos de 1844 acerca del creacionismo mantenido por los teístas:

La creación de la tierra ha recibido un potente golpe por parte de la Geognosia, es decir, de la ciencia que explica la constitución de la tierra, su desarrollo, como un proceso, como autogénesis. La generatio aequivoca es la única refutación práctica de la teoría de la creación. (Marx, 2003, p. 150)

En este fragmento Marx hace mención de la geonogsia, la teoría de Abraham Glottob Werner (1749-1817), considerado el iniciador de la geología histórica, teoría que postulaba que la tierra tendría millones de años y cuya formación dependía del orden de sucesión de las diversas familias o clases de rocas ${ }^{3}$. Con esa referencia, Marx fundamentaba en los hallazgos científicos de su tiempo la crítica a las concepciones de la teología de su época que consideraban la edad de la tierra en unos cuantos miles de años. Con estos comentarios resaltaba la existencia y la preeminencia de la tierra frente a la historia humana conocida y su proceso de autogeneración y autoproducción (Foster, 2004, pp. 187-190). Igualmente, Marx destaca la prioridad ontológica de la naturaleza suscribiendo la tesis de la generatio aequivoca, según la cual el origen de todos los organismos vivientes, la materia orgánica, se encuentra en la materia inorgánica (1974, p. 48). Marx alude a este concepto de la generación espontánea que era, para la época, un concepto que servía de presupuesto a las concepciones materialistas y anti-teístas de todo cuño, entendida como una hipótesis acerca del origen de la vida a partir de la materia inerte. En esa medida, Marx partía del supuesto del

\footnotetext{
${ }^{3}$ Werner había introducido el concepto de 'formaciones geológicas', resaltando así que las diferencias entre los distintos tipos de composiciones minerales encontradas en la tierra radicaban en el modo y tiempo de su formación. Marx conocía muy bien estas teorías, pues en el Instituto de Tréveris había estudiado con el geólogo alemán Johan Steininger, y posteriormente en la Universidad de Berlín asistía a las lecciones de antropología de Heinrich Steffens, geólogo y filósofo natural formado por Werner (Foster, 2004, pp. 187-188).
} 
autogénesis de la naturaleza y sus componentes, descartando la idea de una causa primera y atacando el argumento cosmológico:

Ahora bien, es realmente fácil decirle al individuo aislado lo que ya Aristóteles dice: Has sido engendrado por tu padre y tu madre [...] Ves, pues, que incluso físicamente el hombre debe al hombre su existencia. Por esto no debes fijarte tan sólo en un aspecto, el progreso infinito; y preguntar sucesivamente: ¿Quién engendró a mi padre? ¿Quién engendró a su abuelo?, etc. Debes fijarte también en el movimiento circular; sensiblemente visible en aquel progreso, en el cual el hombre se repite a sí mismo en la procreación, es decir, el hombre se mantiene siempre como sujeto. Tú contestarás, sin embargo: le concedo este movimiento circular, concédeme tú el progreso que me empuja cada vez más lejos, hasta que pregunto, ¿quién ha engendrado el primer hombre y la naturaleza en general? Sólo puedo responder: tu pregunta misma es un producto de la abstracción. Pregúntate cómo has llegado a esa pregunta: pregúntate si tu pregunta no proviene de un punto de vista al que no puedo responder porque es absurdo [...] Cuando preguntas por la creación del hombre y de la naturaleza haces abstracción del hombre y de la naturaleza. Los supones como no existentes y quieres que te los pruebe como existentes. Ahora te digo, prescinde de tu abstracción y así prescindirás de tu pregunta [énfasis añadido]. (Marx, 2003, pp. 150-151)

Según Marx, la pregunta cosmológica planteada no indaga sobre entidades concretas, no pregunta por las causas eficientes de x o y entes reales, suponiendo que hubo un momento en que ni la naturaleza ni sus componentes existieron, surgiendo estos de la nada por medio de un acto creador. Con estas observaciones, el filósofo alemán resalta que responder a la pregunta de la causa primera es inútil, pues parte de un supuesto que hace ininteligible cualquier afirmación sobre el mundo y los entes que lo habitan, esto es, parte del presupuesto de un comienzo de la naturaleza ex nihilo. Por esta razón, Marx insiste en que esta cuestión debe desaparecer tan pronto como se desiste en concebir la naturaleza y su composición material como elementos surgidos de un acto creador anterior a la naturaleza que no parte de la existencia de ningún sustrato material (Marx, 2003, p. 151). De esa manera, Marx asume que la materia no puede surgir de la nada y que esta solo puede transformarse a partir de procesos causales entre entidades con propiedades físico-químicas, esto bajo el presupuesto materialista de la eternidad de la materia y sus procesos de transformación, proveniente de su estudio de la filosofía de Demócrito y Epicuro (Marx, 2010, pp. 440-441).

De esta anotación, así como de los presupuestos materialistas de la generación espontánea y la eternidad de la materia, se infiere que Marx, en su crítica al teísmo, toma la posición naturalista, pues descarta en absoluto cualquier ente sobrenatural, es decir, la invocación de un agente o fuerza que se sitúa por fuera del orden natural y cuyas actuaciones sobre la realidad no pueden ser 
entendidas como parte de dicho orden, siendo esta una característica propia del naturalismo ontológico (Stroud, 1996). Por ello, Marx resalta en los Manuscritos que la pregunta por la causa eficiente de cada ente natural que conduce a la pregunta por el origen de la naturaleza y sus componentes, al hacer abstracción de la existencia de todo substrato físico, implicaría un regreso al infinito, incluso conllevando la pregunta por la causa eficiente de Dios en tanto que creador, lo que a su vez lo supondría como parte del orden natural en tanto que efecto de una causa externa. Entonces, según Marx, para evitar la regresión ad infinitum debe presuponerse como comienzo de la naturaleza a la materia misma y sus procesos de transformación.

Ahora bien, cuando Marx descarta el sobrenaturalismo en su crítica al teísmo, está partiendo de un presupuesto más fundamental en su argumentación: considera real tan solo la substancia que es autosuficiente y que no depende de nada más que de sí misma. Partiendo de este postulado, denominado principio de esencialidad ${ }^{4}$, según el cual solo se puede considerar real aquello que se autogenera y que no depende de nada externo, Marx hace la crítica a las posturas que buscan un origen sobrenatural de la realidad. En consecuencia, según este principio, si una substancia como la naturaleza debe su origen a algo externo entonces no puede ser real. En palabras de Marx (2003), preguntar por la causa primera es poner la naturaleza como un 'no-ser' en tanto que producto de una causa externa a la naturaleza (pp. 151-152).

Dicho presupuesto de esencialidad es de motivos hegelianos. En efecto, para Hegel solo el espíritu absoluto es real en la medida en que no depende de nada externo (Wood, 2004, p. 175). Este concepto proviene, a su vez, de Spinoza, quien en la Ética considera que Dios es la única substancia, que no pueden existir dos o más substancias de la misma naturaleza y que una substancia no puede producir a otra substancia (Spinoza, 1980, proposiciones V y VI). Marx reconoce esta influencia sobre Hegel y señala el elemento spinoziano del Espíritu Absoluto al afirmar que en su obra "la substancia spinozista [...] es la naturaleza metafísicamente disfrazada en su separación del hombre" (Marx \& Engels, 1971, p. 162).

En La sagrada familia, Marx muestra a través de citas de la Fenomenología cómo Hegel considera que se debe abandonar el 'hermetismo' de la substancia, esto es, la concepción de la substancia o lo real como algo 'dado', para elevarla a la conciencia de sí, tratándola como un 'proceso interior', i.e., como una substancia que se autoconstituye a través de un proceso interno de carácter lógico-racional (Marx \& Engels, 1971, pp. 160-161). Efectivamente, para Hegel y los neohegelianos,

${ }^{4}$ Esta denominación es hecha por Allen Wood (2004) en su libro Karl Marx. 
el espíritu es un proceso de auto-expresión, autorrealización y autoconocimiento, considerando al absoluto como espíritu y viendo este proceso como la característica más fundamental de la realidad. Desde la perspectiva del idealismo objetivo, la realidad última es un sistema organizado que tiende a manifestar una cierta forma cuyo proceso dialéctico es su tendencia a su autorrealización. Dicho proceso es uno en que el concepto plantea un mundo que expresa su ser como algo externo (la naturaleza), con el que luego restaura la unidad consigo mismo al comprender el mundo como su propia creación. Este autoconocimiento se logra por medio de mentes finitas que luego se reconocen como expresiones del espíritu absoluto, luego de pasar por una serie de configuraciones de su experiencia consciente (Wood, 2004, p. 201). En últimas, para los filósofos del Absoluto, la naturaleza es un ser esencial pues la realidad (que comprende tanto la realidad física como la realidad social) es un sistema orgánico procesual cuya esencia es de carácter conceptual y cuya finalidad es su autorrealización y autocomprensión racional.

Como se ha dicho, el filósofo de Tréveris acepta como principio la esencialidad de la naturaleza, sin embargo, rechaza tanto la concepción de la substancia de Spinoza, que considera una metafísica superada desde el siglo XVIII por el materialismo francés, como la restauración de este misticismo por Hegel y los neohegelianos, quienes conciben la substancia como 'sujeto' o como 'proceso' (Marx \& Engels, 1971, p. 146-159):

[...] con la victoria lograda sobre el spinozismo, la crítica ha desembocado en el idealismo hegeliano; que renunciando a la "substancia", llegó a otro monstruo metafísico: al "sujeto", a la "substancia como proceso", a la "conciencia infinita de sí", y que la crítica "perfecta y pura" tuvo por resultado final el restablecimiento, bajo la forma especulativa, hegeliana, de la teoría cristiana de la creación. (p. 159)

Marx considera que la substancia de Spinoza es una concepción metafísica sobre la naturaleza, donde confluyen y se confunden entre sí la extensión y el pensamiento como atributos de todo lo existente, siendo el absoluto hegeliano una adaptación de dicha substancia metafísica, pero entendida como sujeto racional que se realiza y se autoconstituye en el proceso del devenir histórico del Espíritu absoluto, a la manera de creador de todo lo real. Así, al discutir en La Sagrada Familia la polémica sobre la interpretación de Hegel surgida entre los neohegelianos Bauer y Strauss, Marx muestra cómo ambos no solo no superan a Hegel, sino que se apegan ambos a sus enseñanzas, tratando la realidad física, la naturaleza, como una creación del movimiento autoconstitutivo de la racionalidad universal que luego deviene espíritu absoluto. De ello Marx concluye que a pesar de presuponer el Espíritu como esencial, a lo que realmente conducen las especulaciones de Hegel y los neohegelianos es a postular la naturaleza como la creación de la conciencia de sí: 
La verdad del materialismo es lo contrario del materialismo; es el idealismo absoluto, es decir, exclusivo, trascendente. La conciencia de sí, el espíritu, es el todo. Fuera de él no existe nada. La conciencia de sí, el espíritu, es el creador omnipotente del mundo, del cielo y de la tierra. El mundo es una manifestación de la conciencia de sí, que debe exteriorizarse y tomar la forma del servidor; pero la distinción entre el mundo y la conciencia de sí no es más que una distinción aparente. La conciencia de sí no diferencia de ella nada real. Mejor dicho, el mundo no es más que una distinción metafísica, una quimera y una imaginación surgidas de su cerebro etéreo. Ella hace desaparecer, pues, la apariencia de que fuera de ella existe algo que habría así concebido; y en lo que ha producido, no reconoce objeto real, esto es, objeto distinguiéndose realmente de ella. (Marx \& Engels, 1971, p. 163)

Según esto, la naturaleza postulada por el espíritu, en la cual este luego se encarna, es una forma de postular filosóficamente la creación ex nihilo de la naturaleza. En consecuencia, para Hegel y los hegelianos, la realidad física se constituye como uno y lo mismo que la conciencia cósmica inmanente a lo realcorpóreo de la naturaleza y no como algo distinto e independiente de cualquier racionalidad, pensamiento o conciencia. En contraste y de la mano de Feuerbach, Marx considera que los hegelianos invierten las cosas en la medida en que consideran el espíritu, la racionalidad, como sujeto creador y no como atributo que se predica de la conciencia humana, la cual es parte de la naturaleza en tanto que atributo de los seres humanos reales, corpóreos y naturales.

Si esto es así, entonces se nos presenta el siguiente interrogante: si, como hemos dicho, Marx parte del presupuesto hegeliano de la esencialidad, pero rechaza su concepción en la filosofía del absoluto icómo es que interpreta la esencialidad de la naturaleza si no es en los mismos términos que Hegel? Siguiendo la interpretación de Allen Wood, podemos decir que Marx acepta en general la descripción que hace Hegel de la realidad, pero rechaza su fundamento metafísico. Para Hegel la realidad (física y social) es un todo orgánico y de carácter procesual, pero esta es el espíritu que se encarna como realidad sensible a partir de una constitución lógico-conceptual. Por su parte, Marx considera desde su concepción materialista que la naturaleza es un ser esencial, i.e., un todo orgánico 'por sí mismo' constituido como una relación de diferentes procesos naturales con tendencias a desarrollos y transformaciones, es decir, la naturaleza es un ser que se autogenera en un proceso material de reproducción y que no depende de una agencia sobrenatural externa o de un desarrollo conceptual de la razón cósmicauniversal. En últimas, Marx considera que esta constitución de la realidad como un todo orgánico es un hecho empírico complejo, que no tiene relación con una constitución lógica que exprese la esencia conceptual del Absoluto, descriptible por principios especulativos o por medio de una Lógica-ontológica. 
Por esto, en contraposición a la metafísica moderna, rescatada luego en la forma especulativa en la filosofía hegeliana, Marx alude en La Sagrada Familia a la tendencia del materialismo francés que se aferró a la física de Descartes: "Descartes ha prestado a la materia una fuerza autocreadora y ha considerado al movimiento mecánico como su acto vital [...] En su física la materia es la substancia única [énfasis añadido], la única razón del ser y del conocimiento" (Marx \& Engels, 1971, p. 147) Según Marx, la aceptación de este principio de la física cartesiana dio frutos en las ciencias naturales contra la teología y especialmente contra la metafísica, pues rechaza de tajo la creación de la naturaleza ex nihilo y todo fundamento ideal y/o sobrenatural de la materia, sus procesos de organización y constitución. En tanto que Marx defiende el materialismo frente al teísmo y al idealismo absoluto, podemos concluir que Marx adhiere a esta concepción de la naturaleza, calificándola como proceso, en últimas, como historia natural.

\subsection{Crítica de la concepción de la naturaleza en Hegel}

Sumado a esto, en los Manuscritos Marx (2003) hace otra reflexión acerca de la realidad externa y la naturaleza en la Crítica de la dialéctica hegeliana y de la Filosofía de Hegel en general. Allí, Marx intenta refutar la concepción de naturaleza presente en el idealismo objetivo de Hegel. En la Enciclopedia, Hegel (2005) afirma:

La naturaleza ha resultado como la idea en la forma del ser-otro. Ya que la idea es así como lo negativo de sí misma o es exterior a sí, [resulta] por tanto [que] la naturaleza no es sólo relativamente exterior frente a esta idea (y frente a la EXISTENCIA subjetiva de ella misma, el espíritu), sino [que] la exterioridad constituye la determinación en que está la idea como naturaleza. (párr. 247)

En este fragmento, Hegel plantea la naturaleza como una manifestación exterior de las determinaciones de la Idea, i.e., de las categorías lógicas unificadoras que expresan todo lo real, que aún no se manifiesta de manera plena en el desarrollo del espíritu, entendido este como la realización del absoluto, i.e., del principio racional, unificador e inmanente de todo lo existente. Con esto, la naturaleza aparece como una forma autoenajenada de la Idea que luego deviene espíritu, este el cual posteriormente asume diferentes formas como expresión de las diversas experiencias que hace la conciencia.

Para Marx, esto significa que Hegel comienza con la 'Idea' en su forma lógica, partiendo de la abstracción absoluta e imponiendo las categorías sobre la naturaleza, de esa manera repitiéndolas en una forma externa para postular racionalmente la realidad sensible del mundo natural. Así, Hegel comienza con 
la Idea abstracta, pasando luego a la Idea mediada (la naturaleza), y retornando a la Idea resultante como espíritu, con ello eliminando la brecha entre el ser y el pensar. En contra de esta concepción, Marx va afirmar que no es el concepto sino los fenómenos materiales mismos los que sirven como fundamento de la realidad, es decir, que el punto de partida es la naturaleza y su punto de llegada es la naturaleza transformada por la mediación de la actividad humana en el trabajo, con ello manteniendo su estatus ontológico independiente, previo a la conciencia y su conceptualización por la mente humana o el Absoluto hegeliano (Stanley, 1998, pp. 454-455).

Con esto dicho, en los Manuscritos Marx pretende objetar la noción del saber absoluto como una superación del objeto de la conciencia, es decir, aquel momento en que el saber de la conciencia es incondicionado en tanto que deja de estar determinado por un objeto exterior. Con ello Marx quiere mostrar que la actitud de Hegel hacia los objetos exteriores es una actitud alienada y su ataque se dirige a contradecir su caracterización de los objetos del saber de la conciencia en sus diversas configuraciones, a los que Hegel considera como meras manifestaciones del espíritu y no como objetos reales e independientes de nuestra representación, captadas por la sensibilidad en la percepción antes de ser pensadas o racionalmente concebidas. Marx (2003) afirma lo siguiente:

Suponed un ser que ni es él mismo objeto ni tiene un objeto. Tal ser sería, en primer lugar, el único ser, no existiría ningún ser fuera de él, existiría único y solo. Pues tan pronto hay objetos fuera de mí, tan pronto no estoy solo, soy otro, otra realidad que el objeto fuera de mí. Para este tercer objeto yo soy, pues, otra realidad que él, es decir, soy su objeto. Un ser que no es objeto de otro ser supone, pues, que no existe ningún ser objetivo. Tan pronto como yo tengo un objeto, este objeto me tiene a mí como objeto. Pero un ser no objetivo es un ser irracional, no sensible, sólo pensado, es decir, sólo imaginado, un ente de abstracción. Ser sensible, es decir, ser real, es ser objeto de los sentidos, ser objeto sensible, en consecuencia, tener objetos sensibles fuera de sí, tener objetos de su sensibilidad. Ser sensible es ser paciente. (p. 193)

Aquí la autoconciencia del saber absoluto de la Fenomenología, aquella que supera las determinaciones externas de sus objetos, es descrita como un 'ser noobjetivo' en contraste con los seres humanos concretos. De acuerdo con Marx, los seres no-objetivos no son seres reales sino abstracciones, seres 'solo pensados'. En cambio, los entes objetivos son aquellos que se encuentran en relaciones con otros entes, que se ven afectados causalmente por otras entidades o que tienen en ellas los objetos de su necesidad: el alimento, el vestido, las relaciones sociales, etc. Así, la actividad y la existencia de un ser tal depende de otros entes realmente existentes y la sensibilidad aparece como un concepto ontológico, esto en tanto que todo ente objetivo se define como un ente que se ve afectado por 
objetos. Como señaló Herbert Marcuse (2016) en su análisis de los Manuscritos, esto proviene de Kant, pues en la Crítica de la razón pura la sensibilidad es la cualidad por la cual se nos presentan los objetos de la experiencia, y estos solo se aparecen a los hombres en la medida en que lo afectan, siendo la sensibilidad la capacidad de verse afectado por objetos. Esto presupone la existencia del mundo exterior como algo independiente de nuestras representaciones y la constitución del mundo nouménico como el ámbito de la sensibilidad.

El presupuesto del que parte Marx en su crítica de la filosofía hegeliana es el principio de reciprocidad ${ }^{5}$, según el cual todo aquello que existe es un objeto sensible y tiene como referencia a otros objetos sensibles. De acuerdo con este principio, para Marx el ser consistiría en las relaciones recíprocas entre una pluralidad de entes que son objetos sensibles los unos de los otros (Stanley, 1998). Con esto Marx va insistir, en contra de Hegel, en la exterioridad de los objetos como condición de los poderes esenciales de todo ser, i.e., como condición de sus poderes causales. En consecuencia, en la medida en que la pluralidad de entes objetivos es la característica de la naturaleza, entonces no puede haber una superación de los objetos ni la anulación de su exterioridad, pues si todo ser es un ser material y natural, entonces todo ser requiere de exterioridad y es externo a otros entes (Marcuse, 2016, p. 461).

De esa manera, bajo el principio de reciprocidad, un 'ser no-objetivo' no puede coexistir con otro ser no-objetivo, ya que esto implicaría que existe en un mundo de objetos sensibles en tanto se ve afectado causalmente por otros objetos, con los cuales mantiene algún tipo de relación. De igual forma, según lo quiere expresar Marx, un ente no-objetivo no puede estar en relación con un ente objetivo por las mismas razones, de tal manera que un ser no-objetivo debe existir solo, sin relaciones con otros entes. Y si se contempla la posibilidad de relaciones entre una pluralidad de entes no-objetivos, no sensibles, tan solo se trataría de meras relaciones entre ideas o pensamientos abstractos en la mente del filósofo contemplativo, quien luego les atribuye una existencia real y más fundamental en la naturaleza (Marx, 2003, p. 204).

De esto se sigue que bajo el principio de reciprocidad todo lo que es natural es sensible, esto es, un objeto que afecta y se ve afectado por otros objetos físicos, por lo cual no puede relacionarse o estar determinado por un ser que no sea objetivo-sensible (Marx, 2003, p. 187). La naturaleza es así la única substancia y no hay nada más fundamental, nada que le preceda o que le sea exterior. Con esto, Marx descarta el punto de vista que pregunta por el proceso de constitución lógica o conceptual de la naturaleza y de esta manera plantea la existencia del mundo como algo real, increado, regido por causas y que no está constituido por

Denominación tomada del trabajo de Allen Wood, 2004, p. 173. 
ningún principio racional estructurador, bien sea la racionalidad y representación humanas o la razón universal representada en el absoluto hegeliano.

\subsection{Contradicción entre esencialidad y reciprocidad: naturaleza de carácter procesual}

Con todo, en la crítica de Marx en el contexto de los manuscritos existe una contradicción, entre el principio de esencialidad y el principio de reciprocidad (Wood, 2004, pág. 179). El primero afirma que la naturaleza es una substancia o ser esencial en la medida en que se autoproduce y no depende de nada externo a sí misma, mientras el segundo principio niega la posibilidad de un ser con dichas características. Esta contradicción se debe a la dificultad que se entrevé de definir a la naturaleza en su totalidad como un ser o un ente. Por ello, parece implausible mantener a la vez el principio de reciprocidad, el principio de esencialidad y la perspectiva de que las cosas finitas y particulares sean en última instancia reales (Wood, 2004).

Esto indica que si Marx adopta la esencialidad de la naturaleza que sirve de crítica al teísmo, entonces debe rechazar el principio de reciprocidad que funciona como una crítica de la filosofía de la autoconsciencia de Hegel, o viceversa. Sin embargo, en la medida en que Marx supone que la Naturaleza es toda la realidad y que por fuera de ella y sus procesos no hay nada, no puede desechar la esencialidad de la naturaleza sin abandonar el naturalismo. Por otro lado, Marx requiere del principio de reciprocidad para destacar la realidad de los entes naturales particulares como objetos sensibles, descartando la posibilidad de la existencia de un ente espiritual incondicionado que determina la constitución del mundo físico y con ello destacando la actividad objetiva del hombre en la percepción y el trabajo, la realidad externa y a los seres humanos como parte de ella comprendida bajo el concepto de Naturaleza. Entonces icómo se puede mantener la crítica de Marx y, en últimas, su naturalismo y realismo en contra de Hegel? La respuesta que propongo es que Marx mantiene la esencialidad y la reciprocidad en la medida en que considera la naturaleza, no como un ente, sino como un sistema de relaciones e interacciones entre entes sensibles particulares, sistema que se ha constituido históricamente por puras interacciones causales entre entes materiales y por fuera del cual no existe nada previo ni más fundamental. En contraste, Hegel tan solo concibe la realidad como un todo orgánico constituido conceptualmente, de tal manera que elimina la contradicción y apariencia de la realidad sensible por medio de la especulación filosófica, esta que Marx denuncia como metafísica y teológica.

Según Marx, Hegel considera la naturaleza como pensamiento alienado y en esa medida solo puede concebir los fenómenos naturales y los productos del hombre como entidades pensadas o meros productos de algún tipo de actividad 
de la razón cósmica del espíritu absoluto, por ello es un puro pensamiento enajenado, vale decir, el pensamiento de un filósofo de carne y hueso y no de una razón cósmica universal inmanente a todo lo real. Por tal razón, dice Marx, en la filosofía hegeliana la apropiación y superación de la coseidad en su exterioridad solo sucede en la conciencia ${ }^{6}$ (Stanley, 1998, pp. 455-456; Marx, 2003, p. 184). Por ello, el pensador comunista precisa cómo es que Hegel entiende la exterioridad y la sensibilidad y cómo estas se superan tan solo como como apropiación en la conciencia de sí del Espíritu absoluto:

No hay que entender aquí la exterioridad como sensibilidad que se exterioriza, abierta a la luz y al hombre sensible. Esta exterioridad hay que tomarla aquí en el sentido de la enajenación, de una falta, de una imperfección que no debía ser. Pues lo verdadero es siempre la idea. La naturaleza es únicamente la forma de su ser-otro [...] el pensamiento abstracto es la esencia [...] El pensador abstracto reconoce, al mismo tiempo, que la esencia de la Naturaleza es la sensibilidad, la exterioridad en oposición al pensamiento que se mece en sí mismo. Pero, simultáneamente, expresa esta oposición de tal forma que esta exterioridad de la Naturaleza, su oposición al pensamiento, es su defecto; que en la medida en que la Naturaleza se distingue de la abstracción es una esencia defectuosa. [...] Es decir, su esencia es algo otro que ella misma [énfasis añadido]. (Marx, 2003, pp. 205-206)

En este apartado, Marx refiere cómo en el sistema hegeliano implícitamente se reconoce la naturaleza como algo real e independiente de la conciencia, pero que en aras del sistema especulativo se concibe como una naturaleza cuya verdad es postulada y expresada en la conciencia universal como Idea abstracta, una conciencia que no es simplemente humana, sino impersonal y encarnada en la naturaleza y la sociedad. En la medida en que esa forma exterior de la naturaleza y sus objetos es tan solo aparente, en el proceso del devenir espíritu absoluto que tiende a su autorealización y autoconocimiento, esas formas se ven superadas en la medida en que dicho espíritu desemboca en el Saber Absoluto, que se sabe como su propio objeto de conocimiento, producto de sí mismo y su desenvolvimiento. Para Marx, esto significa que la naturaleza es la creación de la conciencia de sí, que sus objetos se ven superados en el autorreconocimiento de esta conciencia.

Respecto de la Naturaleza, esto implica que ella no existe independientemente del movimiento del concepto y su constitución lógica, que su realidad sensible es

\footnotetext{
${ }^{6}$ Por eso Marx (2003) afirma de la Fenomenología lo siguiente: "La exterioridad de este pensamiento abstracto [...] La naturaleza tal como es para este pensamiento abstracto; ella es exterior a él, la pérdida de sí mismo; y él la capta también externamente, como pensamiento abstracto, pero como pensamiento abstracto enajenado; finalmente, el espíritu, este pensamiento que retorna a su propia cima, que como espíritu antropológico, fenomenológico, psicológico, moral, artístico-religioso, todavía no vale para sí mismo hasta que, por último, como saber absoluto, se encuentra y relaciona consigo mismo en el espíritu ahora absoluto, es decir, abstracto, y recibe su existencia consciente, la existencia que le corresponde, pues su existencia real es la abstracción" (p. 187).
} 
defectuosa y que solo se efectúa por medio de la superación de sus contradicciones a través de la realización de la Idea. En Hegel, entonces, la sensibilidad de la naturaleza, i.e., su constitución como interacción entre entes sensibles, se resuelve en favor de la esencialidad racional del espíritu que en su realización y autocomprensión resuelve sus contradicciones internas. Pero, desde la perspectiva de Marx, esto no resuelve el asunto, ya que dicho espíritu, en tanto que ideal, no sensible, no puede contener ni determinar la materialidad del mundo que solo admite relaciones causales con entes físicos, esto de acuerdo con la reciprocidad que Marx le enrostra al 'monstruo metafísico' del Espíritu Absoluto.

De cierta forma, Marx critica a Hegel por sostener un dualismo psico-físico en su concepción de la naturaleza, en la medida en que el filósofo idealista considera que esta se constituye a través de un proceso de carácter conceptual y no enteramente físico-causal. Por ello, Hegel (2005) niega la noción de historia natural en su sentido materialista, pues si bien cree que la naturaleza debe ser considerada de manera procesual, i.e., constituida en el tiempo de manera evolutiva, el autor de la Fenomenología considera que es un error concebir que este proceso es material e independiente de las determinaciones de la Idea, pues "La metamorfosis incumbe solamente al concepto en cuanto tal, ya que únicamente el cambio de éste es desarrollo" (Hegel, 2005, pp. 308-309), esto es, la transformación y surgimiento de los entes sensibles en la naturaleza solo son tales en virtud del desenvolvimiento del concepto y no en tanto procesos físicocausales. Por eso, Hegel (2005) precisa:

Es una representación torpe, propia de la vieja filosofía de la naturaleza, y también de la moderna, contemplar el proceso de formación y el paso desde una forma y esfera de la naturaleza a otra superior, como una producción externa y efectivamente real, que sin embargo, para hacerla más clara, se retrotrae a la oscuridad del pretérito [...] Esas representaciones nebulosas, en el fondo sensibles, como particularmente lo es p. e. el surgir de las plantas y animales desde el agua, y después el surgir de los animales desarrollados desde los inferiores, etc., han de ser expulsadas por la contemplación pensante. (párr. 249)

Es decir que, para Hegel, los procesos naturales toman lugar en un nivel inferior y así no cumplen ningún rol constitutivo en el movimiento del concepto, y más bien están determinados por el movimiento de este (Stanley, 1998, p. 462). Por esta razón, Marx (2008) afirma en El Capital que "Para Hegel el proceso del pensar, al que convierte incluso, bajo el nombre de Idea, en un sujeto autónomo, es el demiurgo de lo real; lo real no es más que su manifestación externa" (pp. 19-20).

Marx, en cambio, reafirma la prioridad de la naturaleza frente a la conciencia, su punto de partida es una naturaleza independiente, opuesta a la concepción 
hegeliana de una naturaleza dependiente del pensamiento o de una racionalidad universal inmanente. Así, considera que la naturaleza está compuesta de materia inorgánica, la cual es eterna y que constituye a los seres objetivos, i.e., sensibles, condicionados por relaciones causales; de esta surgen por 'generación espontánea' los entes constituidos por materia orgánica, i.e., los seres vivos entre los cuales se encuentran los seres humanos (Marx, 1974, p. 48). En este sentido, Marx hace una distinción entre el mundo de las causas, ámbito de la naturaleza, y el mundo de las razones, ámbito humano y social que es producto del trabajo y su despliegue en la historia, señalando que no es posible — como creen Hegel y los neohegelianos - que los entes que habitan la naturaleza estén constituidos por algún tipo de concepto inmanente, dado que los cambios y transformaciones de estos entes solo ocurren en el orden de la causalidad inherente a las relaciones entre objetos sensibles.

Con lo dicho, se advierte que la contradicción entre el principio de esencialidad y el principio de reciprocidad más arriba mencionado, solo se mantiene si consideramos que la naturaleza, en la filosofía de Marx, es comprendida como una cosa o ente, lo que implicaría rectificar el concepto de Naturaleza, una pretensión que es ajena a las consideraciones del pensador comunista. Por ello, parece más conveniente y más acorde con la perspectiva del filósofo alemán, considerar la naturaleza de manera procesual, i.e., como historia natural, como un sistema que es resultado de sus propios presupuestos materiales y desarrollos causales internos, constituyéndose como un conjunto de interacciones entre los entes objetivos que la componen. La Naturaleza cumple así el principio de esencialidad en la medida en que no depende de nada externo o abstracto, como un ser sobrenatural o un principio racional estructurador a la manera del absoluto hegeliano. Es un sistema que surge a partir de un proceso que va de la constitución de los entes de materia más simple, la materia inorgánica, a las formas más complejas, aquellos organismos vivos constituidos por la materia orgánica, entre los cuales se incluyen los seres humanos. La naturaleza es el conjunto de todas las interacciones y relaciones causales entre entidades físicas que habitan el mundo, pero no es ella misma un ente particular sensible. Por otra parte, los entes que componen el sistema natural son objetivos en tanto cumplen con el principio de reciprocidad, pues se encuentran inmersos en múltiples relaciones causales, espaciales y temporales, y no dependen del absoluto y su negatividad para su constitución. De aquí que contrario a lo que plantea Allen Wood - para Marx sea plausible defender ambos principios y la existencia de entes finitos.

\section{El realismo de Marx}

Con lo dicho hasta el momento, queda claro que Marx se aparta del idealismo predicando un naturalismo bien particular. A pesar de ello, vimos que en su sistema quedan algunos residuos del sistema hegeliano en la medida en que 
acepta la realidad como un todo orgánico de carácter procesual. Sin embargo, esto no implica que Marx simplemente asuma una nueva forma de idealismo, pues el autor de El Capital no asume su premisa fundamental: considerar que la realidad no existe independientemente de la conciencia. Como afirma Díaz (1986), la preocupación de Hegel se centra en eliminar todo vestigio de la 'cosa en sí' kantiana, por lo cual asume que "la conciencia es la realidad absoluta, fuera de la cual nada puede ser pensado, ni ser" (p. 122). En últimas, el Idealismo es un antirrealismo en el sentido de que no concibe que la realidad y sus componentes tengan un modo de existencia por fuera de la razón universal del Absoluto. Marx, en cambio, asume que la naturaleza es la única realidad, por fuera de la cual no hay nada más fundamental o anterior en el tiempo, además, concibe que esta naturaleza es independiente de la conciencia, la cual Marx postula como una conciencia finita, humana, histórica y fruto del proceso de despliegue del trabajo sobre la naturaleza. Sin embargo, muchos marxistas o varios de sus intérpretes han desconocido o relativizado el realismo de Marx.

Este es el caso del célebre trabajo El concepto de Naturaleza en Marx de Alfred Schmidt (1977); en este se expone la visión según la cual Marx acepta la "prioridad ontológica" de la Naturaleza, pero solo concibiéndola como término de una mediación, es decir, que la naturaleza solo es tal en la medida en que es mediada por el trabajo del hombre para la producción de valores de uso, más específicamente:

La naturaleza es para Marx un momento de la praxis humana y al mismo tiempo la totalidad de lo que existe [...] Marx no se propone reemplazar simplemente el espíritu del mundo de Hegel por un principio igualmente metafísico, como sería una sustancia material del mundo [...] El idealismo acierta al considerar que el mundo está mediado por el sujeto. Marx piensa, sin embargo, que este pensamiento sólo puede aceptarse en todo su alcance en tanto demuestra la importancia que tiene el peculiar pathos del "producir", de Kant a Hegel: el productor de un mundo objetivo es el proceso vital socio-histórico de los hombres. (Schmidt, 1977, p. 22)

Para sustentar su tesis, Schmidt señala las críticas de Marx a Feuerbach en la Ideología Alemana, en las que le reprocha que no advierta cómo la naturaleza se ve todo el tiempo trastocada por la industria, concluyendo con ello que Marx no concibe la naturaleza como algo independiente del trabajo. De esa manera, según Schmidt, Marx no cae en un 'materialismo ontológico', es decir, realista, de esa forma restaurando el papel activo del sujeto propuesto por el idealismo; sin embargo, el autor parece confundir tesis ontológicas, antropológicas y epistemológicas en su examen del concepto de Naturaleza en Marx (Schmidt, 1977, pp. 27-30)

\footnotetext{
${ }^{7}$ Argumentos similares se encuentran en Leszek Kolakowski, Sydney Hook, Shlomo Avineri, Jean-Yves Calvez y en Lukács (en sus primeras obras) (Wood, 2004, p. 190).
} 
Estas interpretaciones yerran al considerar a Marx como un antirrealista, incluso recayendo en ciertas contradicciones. Desde mi perspectiva, parte de la confusión que entraña la interpretación de Marx proviene de los problemas concernientes al tratamiento filosófico del realismo. Según John Searle (1997), en su defensa de un realismo externo como una tesis ontológica, son cuatro los errores que generalmente se cometen con respecto a la disputa realismo/ antirrealismo: considerar que el realismo implica o es equivalente a una teoría de la verdad (teoría de la verdad por correspondencia); equiparar el realismo con una epistemología; tratar al realismo como una concepción metafísica substantiva de la realidad, i.e., como una tesis que plantea el modo en que de hecho son las cosas en la realidad; y concebir el realismo como una tesis que afirma la existencia de un léxico o método privilegiado para describir la realidad (Searle, 1997). A continuación, trataré brevemente cada uno de estos errores de interpretación con respecto al realismo de Marx.

\subsection{Realismo y teoría de la verdad}

Se suele considerar que el realismo implica o es idéntico a la teoría de la verdad por correspondencia, esto es, la teoría que concibe verdaderos solo aquellos enunciados que se corresponden con estados de cosas en el mundo. Pero, como asegura John Searle, esto no es correcto, pues la tesis de que la realidad existe independientemente de nuestras representaciones es una tesis ontológica y no semántica, i.e., no es una teoría acerca de qué constituye el significado de 'verdadero'. Además, es consistente ser realista y rechazar la teoría de la verdad por correspondencia, p. ej., adhiriendo a una teoría coherentista de la verdad (Searle, 1997, p. 163). Este error de concebir el realismo como una teoría de la verdad, se presenta en diversas interpretaciones de la obra de Marx en su concepción de la realidad y la naturaleza. Así, se ha interpretado la segunda tesis sobre Feuerbach como una muestra del supuesto antirrealismo de Marx:

El problema de si puede atribuirse al pensamiento humano una verdad objetiva no es un problema teórico, sino un problema práctico. Es eh la práctica donde el hombre debe demostrar la verdad, es decir, la realidad y el poder, la terrenalidad de su pensamiento. La disputa en torno a la realidad o irrealidad del pensamiento -aislado de la práctica- es un problema puramente escolástico. (Marx, 1974, p. 666)

Como afirma Allen Wood (2004), este pasaje ha sido interpretado por Leszek Kolakowski como una teoría pragmatista de la verdad (p. 181)

Kolakowski's purpose in ascribing a 'pragmatist concept of truth' to Marx is to support an essentially idealist reading of Marx, according to which

${ }^{8}$ La traducción es propia. 
Marx holds that 'the existence of things comes into being simultaneously with their appearance as a picture in the human mind.' The idea seems to be that since (Kolakowski alleges) 'the pragmatic concept of truth is clearly not compatible with the classical definition of "truth" as correspondence between our thoughts or judgments and a reality independent of them', Marx must not believe there is such a reality. (p. 182)

El argumento afirma que, en la medida en que Marx no define la verdad como correspondencia, entonces no interpreta la realidad como independiente de los juicios o representaciones humanas. Sin embargo, no es incompatible admitir una teoría pragmatista de la verdad y considerar que la verdad de un juicio depende de su correspondencia con un estado de cosas en el mundo, esto de acuerdo con un criterio de utilidad práctica que permita atribuir dicha correspondencia entre juicios y estados fácticos — por ello William James veía su teoría de la verdad como una versión de la teoría de la correspondencia (Wood, 2004, p. 182)—. Por otra parte, de la segunda tesis sobre Feuerbach no se puede deducir que no puede ser el caso que exista una realidad independiente de las representaciones humanas, por lo que afirmar tal cosa, para el filósofo americano, es incurrir en un non sequitur (Wood, 2004, p. 182). A lo sumo, se puede decir que una teoría de la verdad por correspondencia implica necesariamente una tesis ontológica realista, en tanto propone como condición de verdad la correspondencia del contenido del enunciado con estados fácticos. Pero lo contrario no es cierto, pues el realismo no implica necesariamente la teoría de la verdad por correspondencia y, por ende, es compatible con cualquier otra teoría de la verdad, p. ej., una teoría coherentista. De todas formas, en ningún caso es posible atribuir con certeza alguna de estas proposiciones acerca de la verdad a Marx, quien nunca se ocupó en detalle del tema, y aunque pareciera sugerir una teoría pragmatista en la segunda tesis sobre Feuerbach, de ello no se seguiría un rechazo implícito de Marx al realismo ontológico.

\subsection{Realismo y posición epistémica}

De otra parte, se ha afirmado que el realismo implica abrazar una determinada postura epistemológica, p. ej., una epistemología fundacionalista o un realismo ingenuo sobre la adquisición de conocimiento. Según Searle (1997), es erróneo considerar el realismo como una tesis epistémica, en la medida en que postular que la realidad existe independiente de nuestras representaciones no implica afirmar una determinada tesis acerca de cómo adquirimos conocimiento de dicha realidad (p. 164).

En relación con nuestro tema, se ha asumido que Marx niega el realismo ontológico en la medida en que no parte de una epistemología fundacionalista, en tanto que considera que el conocimiento es el resultado de ciertos procesos de socialización en el ámbito de las relaciones sociales de producción y, por ello, 
sujeto a contingencias sociohistóricas. Esto se basa en ciertas interpretaciones según las cuales no puede haber una separación entre el pensamiento humano y la existencia, dado que el pensador de Tréveris resalta el momento de la praxis como concepto mediador entre el sujeto y el objeto (Wood, 2004, p. 190; Schmidt, 1977, pp. 128-129). Uno de los pasajes en que se basan algunos de estos comentarios, es un fragmento de Marx sobre la filosofía de Hegel en los Manuscritos: "Pero también la Naturaleza [énfasis añadido] tomada en abstracto, para sí, fijada en la separación respecto del hombre, no es nada [énfasis añadido] para el hombre" (Marx, 2003, p. 204). Se ha considerado que con esto Marx afirma que la naturaleza, entendida como la realidad en su totalidad, no puede existir o concebirse sin relación con el hombre, que es 'nada' aparte de esta relación.

Empero, esa conclusión es incorrecta, ya que el admitir que la naturaleza de nuestro conocimiento no es de carácter contemplativo, sino práctico a través de la acción humana sobre la naturaleza en el trabajo, no implica negar la independencia de la naturaleza y la realidad respecto de los estados de conciencia. De hecho, tal evidencia textual tan solo muestra la crítica de Marx a Hegel, en la medida en que Marx hace esta afirmación en el contexto de su crítica a la filosofía de la naturaleza del idealismo absoluto que no concibe la posibilidad de una naturaleza no puesta por el espíritu en su desenvolvimiento histórico, siendo que esta conciencia espiritual es, para Marx, no otra cosa sino la conciencia humana del filósofo contemplativo, pero postulada como conciencia impersonal y universal. De ahí que, según Marx (2003), desde el punto de vista del filósofo contemplativo "la naturaleza [...] para sí, fijada en la separación respecto del hombre, no es nada para el hombre" (p. 204). Y, aún en el caso de que dicho pasaje fuera una afirmación de Marx, este tan solo afirmaría que la naturaleza en abstracto no es 'nada para el hombre', i.e., no es nada en relación con la postura teórica o práctica del ser humano, lo cual no evidencia en absoluto un antirrealismo, pues como se ve, no refiere a una tesis sobre el modo de existencia de la naturaleza sino a la actitud del ser humano frente a ella. De cualquier forma, como dijimos, esto no vale como una afirmación de Marx, además él mismo en los Manuscritos adhiere al realismo cuando dice que los objetos del ser humano y sus impulsos existen fuera de él y son independientes de él (Wood, 2004, p. 191; Marx, 2003, p. 192).

\subsection{Metafísica substantiva de la realidad}

Por otro lado, se ha concebido que el realismo implica o es equivalente a una teoría acerca de cómo es de hecho el mundo, una teoría acerca de cómo está constituido, considerando que la realidad está compuesta de un determinado tipo de objetos o de un determinado tipo de procesos. En relación con esto, Searle (1997) afirma que el realismo no se pregunta por cómo son los constituyentes 
últimos del mundo, sino que tan solo plantea que este existe independientemente de cómo lo representamos. Según sus palabras: "El realismo no dice cómo son las cosas, sino sólo que tienen una manera de ser", esto es, que existen independientemente de nuestra conciencia o mente (p. 165).

Esta cuestión de la metafísica substantiva se ha postulado con respecto a la relación entre el naturalismo y el realismo en el pensamiento de Marx, específicamente con respecto a la problemática de la 'dialéctica' marxiana. En la Ideología Alemana, Marx hace la siguiente precisión frente al materialismo contemplativo de Feuerbach:

No ve que el mundo sensible que le rodea no es algo directamente dado desde toda la eternidad y constantemente igual a sí mismo, sino el producto de la industria y del estado social, en el sentido de que es un producto histórico, el resultado de la actividad de toda una serie de generaciones [...] [que] sigue desarrollando su industria y su intercambio y modifica su organización social en arreglo a las nuevas necesidades. Hasta los objetos de la "certeza sensorial" más simple le vienen dados solamente por el desarrollo social, la industria y el intercambio comercial. (Marx, 1974, p. 47)

En este pasaje, el autor del Manifiesto le reprocha a Feuerbach que no advierta cómo el trabajo social ha transformado la naturaleza, modificando los ecosistemas por medio de la industria. Esto ha sido interpretado por algunos comentaristas como un signo de antirrealismo, en cuanto se ve a la naturaleza como algo constituido por la actividad humana y no ya como algo dado antes del hombre, en últimas, como un antirrealismo en la medida en que Marx afirma cómo está compuesta la naturaleza. Sin embargo, estos comentarios de Marx tan solo funcionan como una cualificación de su naturalismo y de ninguna forma como antirrealismo, ya que lo único que implica la tesis marxiana es que el trabajo humano y las fuerzas productivas generan grandes impactos de los ecosistemas y organismos vivientes, de ningún modo aseverando por ello la dependencia de la naturaleza respecto del ser humano para su existencia. En últimas, implicaría simplemente una concepción acerca de cómo la actividad humana causa ciertos efectos en la naturaleza, siendo así una afirmación sobre la cualidad de los componentes de la naturaleza y no sobre el modo de existencia de la misma, esto es, un modo de existencia independiente de las actitudes humanas. Además, esta afirmación de Marx, aunque correcta, no debe ser tomada en un sentido fuerte, es decir, considerando que toda la naturaleza se ve constituida por el trabajo humano, pues evidentemente aún hoy pueden encontrarse vestigios de ecosistemas terrestres suficientemente independientes de las sociedades, sin contar con los componentes ajenos a nuestro planeta que todavía hoy permanecen intocados 
por nuestra agencia y que hacen parte de la realidad física, i.e., el universo. De tal manera que la afirmación de Marx de que esa naturaleza virgen "no existe ya en ninguna parte" (Marx, 1974, p. 48), es bastante exagerada.

Esto va unido con la cuestión de si existe una dialéctica de la naturaleza en el pensamiento de Marx, tal como la planteó Friedrich Engels (1968) en el Anti-Duhring. Varios comentaristas han descartado tal posibilidad (Lukács, 1970; Merleau-Ponty, 1964; Jaramillo, 2017), bajo la consideración de que, para Marx, solo se puede hablar de dialéctica en referencia al metabolismo entre ser humano y naturaleza por medio de la praxis del trabajo, esto es, considerando dialéctico solo el proceso de producción de valores de uso por el hombre a través de la intervención de los substratos materiales para la satisfacción de necesidades. Con ello se descarta la dialéctica como un proceso inherente a los procesos naturales mismos por fuera de la actividad humana. Esto se interpreta como una muestra de un supuesto antirrealismo en Marx, que argumenta que en él solo la relación humano-naturaleza es dialéctica. Esta postura se sustenta en uno de los pasajes de El Capital:

[...] el trabajo es, independientemente de todas las formaciones sociales, condición de la existencia humana, necesidad natural y eterna de mediar el metabolismo que se da entre el hombre y la naturaleza, y, por consiguiente, de mediar la vida humana [...] En su producción, el hombre sólo puede proceder como la naturaleza misma, vale decir, cambiando, simplemente, la forma de los materiales". (Marx, 2008, p. 53)

En la primera parte de este pasaje, el metabolismo (stoffwechselprozess) — término cuya raíz griega significa el proceso de ingerir alimentos y su transformación en sangre y energía (Jaramillo, 2017, p. 52) - es descrito como un proceso por el cual el hombre transforma la materia para satisfacer necesidades humanas. Más adelante, dicho proceso se describe como un cambio en 'la forma de los materiales' a través de una actividad material, que en el caso del ser humano, es el trabajo. Dicho proceso, el metabolismo y/o 'intercambio orgánico' entre hombre y naturaleza, es interpretado como "...el ámbito a partir del cual se puede hablar de una "dialéctica" no en o de sino a través de la naturaleza" (Jaramillo, 2017, p. 52), negando con ello la posibilidad de una dialéctica de la naturaleza como dinámica de relación entre organismos vivientes y la materia inorgánica por fuera de toda intervención humana. Contra esta posición, Wood (2004) y Stanley (1998) afirman que no se puede sostener que Marx niegue un carácter dialéctico a la naturaleza, pues aunque él no trató la cuestión en detalle, por un lado, el filósofo comunista describe la dialéctica como reciprocidad y procesualidad de la naturaleza y, por otro, en varios escritos considera que "los 
principios de la dialéctica han sido verificados tanto en la historia como en las ciencias naturales" (Wood, 2004, p. 223) .

En ese sentido, la interpretación del pasaje de El Capital desconoce el uso que le da Marx al concepto 'metabolismo', lo que conduce a la conclusión de que dicho proceso no puede darse en la naturaleza misma y, por ello, que no pueda hablarse de una dialéctica de la naturaleza. Por consiguiente, dicha interpretación solo puede sostenerse si se supone una equivalencia entre 'metabolismo' y 'trabajo', tal que solo puede hablarse de metabolismo en tanto haya trabajo humano sobre la naturaleza. Pero la afirmación de Marx en El Capital no implica tal equiparación, pues Marx era consciente de que el metabolismo es un proceso que está presente en el funcionamiento normal de todo ser vivo, razón por la que afirma en el mismo pasaje: "En su producción, el hombre sólo puede proceder como la naturaleza misma, vale decir, cambiando, simplemente, la forma de los materiales" (Marx, 2008, p. 53). Esto se explica porque Marx utilizaba el término de metabolismo de la misma manera en que lo utilizaba el físico británico John

\footnotetext{
${ }^{9}$ [La traducción es propia]. En este aspecto, vale recordar que hay al menos dos comentarios de Marx donde suscribe la posibilidad de una dialéctica de la naturaleza dado que, según él, las leyes de la dialéctica han sido verificadas tanto en la historia como en las leyes de la naturaleza. En una carta de Marx a Engels fechada el 22 de junio de 1867, Marx afirma: "Ya verás, además, como al final de mi capítulo III, donde se esboza la metamorfosis del maestro artesano en capitalista, a consecuencia de cambios simplemente cuantitativos, menciono en el texto el descubrimiento de Hegel sobre la ley de la brusca conmutación del cambio únicamente cuantitativo en cambio cualitativo como ley verificada inmediatamente en historia y en las ciencias de la naturaleza" (Marx \& Engels, 1973, p. 58). También en el capítulo IX. Tasa y Masa del plusvalor de El Capital, Marx (2008) afirma: "El poseedor de dinero o de mercancías no se transforma realmente en capitalista sino allí donde la suma mínima adelantada para la producción excede con amplitud del máximo medieval. Se confirma aquí, como en las ciencias naturales, la exactitud de la ley descubierta por Hegel en su Lógica, según la cual cambios meramente cuantitativos al Ilegar a cierto punto se truecan en diferencias cualitativas" (p. 379). En seguida, en la tercera edición de El Capital se introdujo un pie de página en el que Marx explica cómo esa ley de la Lógica de Hegel se ve confirmada en la 'serie homóloga de los hidrocarburos', según la cual "mediante la adición puramente cuantitativa de $\mathrm{CH} 2$ a la fórmula molecular se crea cada vez un cuerpo cualitativamente diferente" (Marx, 2008, pp. 374-375), presentando esto como evidencia de un principio dialéctico de la naturaleza descubierto por Hegel, en este caso en la química molecular. Además de estos comentarios, hay razones de peso para creer que Marx no solo creía en una dialéctica de la naturaleza, sino que además abrazó con entusiasmo las elucubraciones de Engels al respecto. Por ejemplo, Marx enseñó una carta que recibió de Engels el 30 de mayo de 1873, en la que este le comentaba a Marx sus primeras especulaciones acerca de una dialéctica de la naturaleza, a Carl Schorlemmer, químico alemán amigo suyo y de Engels, entusiasta de la causa comunista y lector de Hegel, quien aprobó con varios comentarios las especulaciones de Engels con respecto a una dialéctica naturalizada (Marx \& Engels, 1973, p. 78). Y ya en una carta a Ludwig Kugelmann fechada el 6 de marzo de 1868, refiriéndose precisamente a Duhring, Marx afirma: "Duhring sabe perfectamente que mi método de exposición no es el mismo de Hegel, pues yo soy materialista y Hegel es idealista. La dialéctica de Hegel es la forma fundamental de cualquier dialéctica, pero sólo cuando conseguimos desnudarla de su ropaje místico, y es esto lo que distingue mi método..." (Marx \& Engels, 1973, p. 61) mientras que el 9 de mayo de 1868 Marx escribía a Joseph Dietzgen: "[...]Cuando me haya librado de mi fardo económico, escribiré una «Dialéctica». Las leyes correctas de la dialéctica ya están contenidas en Hegel; es cierto que bajo una forma mística. Se trata de despojarlas de esta forma [...]" (Marx \& Engels, 1973, p. 65).
} 
Tyndall y el fisiólogo alemán Theodor Schwann, científicos a quienes había leído y que usaban dicho concepto para referir al intercambio de materia y energía entre las células y su medio (Foster, 2004, p. 248).

En consecuencia, Marx refería al metabolismo como analogía para explicar el papel del trabajo en la vida humana, sin reducir el metabolismo al trabajo y sin negar la existencia de dicho proceso en la naturaleza misma, dando lugar a una perspectiva dialéctica de la naturaleza como procesualidad y relaciones recíprocas entre entes de materia orgánica e inorgánica, siendo así una característica independiente del ser humano y sus actitudes frente a la naturaleza. Con esto se descarta que en la obra de Marx no sea posible hablar de un carácter dialéctico de la naturaleza y, por otra parte, que esto constituya un desafío a la atribución de un realismo a su filosofía, pues el hecho de que la naturaleza sea considerada dialéctica o no, no implica negar que el modo de existencia de la realidad es independiente de nuestras representaciones o de una supuesta conciencia universal hegeliana.

\subsection{Realismo y léxico privilegiado}

Por último, se tiende a considerar que el realismo implica la existencia de un léxico privilegiado que puede dar cuenta de la realidad, es decir, un esquema conceptual único con el que se puede describir la realidad en su totalidad. Frente a esto, Searle afirma que dicha postura es incorrecta, ya que la tesis de que la realidad existe independientemente de nuestras representaciones no implica un léxico único y además es compatible con el relativismo conceptual, es decir, con asumir la existencia de diversos esquemas conceptuales inconmensurables entre sí para describir la realidad.

Todo esto se relaciona con la pregunta de si en el pensamiento de Marx se plantea algo como un léxico privilegiado para describir la realidad, en últimas, si hay un método o una lógica dialéctica de la naturaleza. Como se ha dicho hasta aquí, Marx recoge de Hegel su descripción de la realidad como totalidad orgánica, por ende, como una totalidad constituida de relaciones recíprocas e interdependientes entre entidades sensibles que se conforma de manera procesual en la historia natural. Pero Marx rechaza la perspectiva de una constitución lógica del mundo en la medida en que rechaza el idealismo y concibe la naturaleza como el orden de las causas. A pesar de ello, él sí cree que tanto la realidad física como social son de carácter dialéctico, por ello, considera que la mejor manera de describir dicha realidad es de manera dialéctica, i.e., mediante la operación intelectual de pensar en conceptos universales las relaciones entre entidades concretas a partir de procesos de abstracción complejos. Según Wood, esto tan solo significa que para Marx la dialéctica es un hecho empírico y una operación intelectual para comprender el mundo estructurado como totalidad orgánica (Wood, 2004, pp. 217-223). 
Dicho esto, se puede pensar razonablemente que la perspectiva de Marx implica aceptar implícitamente un isomorfismo entre pensamiento dialéctico y mundo, por ende, proponiendo una 'dialéctica de la naturaleza' y un 'léxico privilegiado' para describir y explicar la realidad. Como se dijo arriba, este tipo de tesis se intepretan como una consecuencia de asumir un realismo ontológico, lo que se pretende relativizar o negar por aquellos comentaristas que ven en la 'dialéctica de la naturaleza' una 'metafísica de la materia' o un signo de 'positivismo' inaceptable (Jaramillo, 2017, pp. 53-54; Merleau-Ponty, 1964). Por tales razones se considera que el método dialéctico solo puede ser utilizado como un análisis de la realidad social mas no de la realidad física, con ello apoyando un supuesto antirrealismo o evitando una 'ontologización' de la dialéctica marxiana ${ }^{10}$.

Empero, Marx acepta una dialéctica de la naturaleza y la existencia de un léxico privilegiado, muy a pesar de los comentaristas que niegan tal cosa. Según Wood, la dialéctica marxiana aplicada al sistema social, es tan solo una manera de explicar dicho sistema como una totalidad orgánica con tendencias internas hacia ciertos desarrollos en su propia constitución, siendo tales desarrollos inherentes a las relaciones entre las partes constitutivas del sistema. Siendo que, según lo que hemos dicho, esta dialéctica se concibe también propia de la naturaleza, tales principios que Marx aplica a la realidad social pueden, consistentemente, aplicarse a la realidad física, constituyendo así un léxico o método privilegiado que se muestra como un conjunto de principios generales que guían la adquisición de conocimiento sobre la realidad (Wood, 2004, pp. 218-219) ${ }^{11}$. Adicionalmente, aceptar dicho método dialéctico como aplicable a la naturaleza, no refuta la intepretación de Marx como un realista pues, como afirma John Searle, el realismo no implica necesariamente la tesis de un léxico o método privilegiado para dar cuenta de la realidad, por lo cual el realismo se mantiene, bien porque se concibe posible tal lenguaje o método privilegiado, o bien porque se enuncie la existencia de diversos esquemas conceptuales inconmensurables sobre la realidad y la inexistencia de un isomorfismo entre mundo y lenguaje.

\footnotetext{
${ }^{10}$ De hecho, el legado de la Dialéctica de la Naturaleza de Engels se tradujo en la obra The Dialectical Biologist de Richard Levins y Richard Lewontin, quienes intentan esbozar un nuevo materialismo dialéctico como 'dialéctica de la naturaleza' Levins \& Lewontin, 1985.

${ }^{11}$ A partir de la excelente exposición sobre la dialéctica hegeliana y marxiana que hace Allen Wood en la que refiere a los orígenes kantianos del concepto, considero que la así llamada 'dialéctica', tanto en Hegel como en Marx, es un concepto demasiado general y sin mayor contenido filosófico. De cierta forma, sirve tan solo como una descripción muy abstracta de la realidad entendida como 'totalidad orgánica' 'procesualidad' o incluso cierta forma de 'teleología' de todo lo existente. Pero no veo cómo esto reemplaza una concepción naturalista tradicional y sus concepciones de la causalidad. Con ellos suscribo al comentario de Jon Elster (1992) respecto al denominado 'materialismo dialéctico': "la forma dialéctica codificada en el materialismo dialéctico es bastante trivial. A veces equivale a decir poco más que existen interconexiones generales entre todas las cosas y otras veces se utiliza como un concepto extravagante para designar procesos de retroalimentación" (p. 198).
} 


\section{Naturalismo y realismo en la obra de Marx}

En este artículo calificamos el naturalismo de Marx como una respuesta al teísmo y a la metafísica hegeliana, con el cual se describe la realidad como un sistema compuesto de las relaciones e interacciones entre entidades sensibles que no dependen, en su origen, constitución y transformación, de ninguna agencia sobrenatural ni de ningún principio racional esencial estructurado como el movimiento del concepto del Espíritu hegeliano. Con ello, Marx plantea una escisión radical entre el orden de las causas (la realidad física o naturaleza) y el orden de las razones (predicado de la realidad social y la cognición humana), descartando todo rezago de idealismo hegeliano. De otra parte, mostramos el realismo de Marx, que se muestra como la concepción de que la realidad (comprendida bajo el concepto de 'naturaleza') existe independientemente de la conciencia o mente humana y de la supuesta conciencia cósmica/universal del absoluto. Dicho realismo no implica ninguna de las tesis antropológicas y/o epistemológicas que se atribuyen a Marx, que a menudo se presentan como contraejemplos a la intepretación realista de su obra.

Con lo dicho, se advierte que el naturalismo ontológico de Marx es lógicamente independiente de su realismo, pues el primero plantea el tipo de constitución de la realidad y el segundo el modo de existencia de la realidad. Por ello, las intepretaciones antirrealistas de Marx son más bien análisis de su naturalismo y, por ello, no constituyen un desafío serio a las intepretaciones realistas. En consecuencia, podemos asegurar que hay un alejamiento más radical del autor de El Capital con respecto a Hegel de lo que se suele afirmar y una mayor cercanía a un naturalismo ontológico y metodológico contemporáneo.

\section{Referencias}

Díaz, J. A. (1986). Estudios sobre Hegel. Universidad Nacional de Colombia.

Elster, J. (1992). Una Introducción a Karl Marx. Siglo XXI Editores.

Engels, F. (1968). Anri-Dühring: La subversión de la ciencia por el señor Eugen Dühring. Grijalbo.

Feuerbach, L. (1984). Tesis provisionales para la reforma de la filosofía. Orbis.

Foster, J. B. (2004). La ecología de Marx: Materialismo y Naturaleza. Ediciones de Intervención cultural-El viejo Topo.

Gonzáles, N. (2010). Karl Marx, lector anómalo de Spinoza. Montesinos. 
Hegel, G. (2005). Enciclopedia de las Ciencias Filosóficas. Alianza Editorial.

Jaramillo, R. (2017). Naturaleza y Praxis en relación con el proceso del conocimiento: Sobre la equívoca noción engelsiana de 'dialéctica de la naturaleza' y sus implicaciones. En R. Jaramillo (comp.), La primacía de la Praxis: Ensayos Críticos en torno a Marx y el marxismo (pp. 51-68). Ediciones Veramar.

Levins, R. \& Lewontin, R. (1985). The Dialectical biologist. Harvard University Press.

Little, D. (1986). The Scientific Marx. The University of Minnesotta Press.

Livingstone, D. (2017). Naturalism. En Rosenberg, A. \& Mclntyre, L. (Eds.), The Routledge Companion to Philosophy of Social Science (pp. 159-168). Routledge.

Lukács, G. (1970). Historia y Conciencia de Clase. Instituto del Libro.

Marcuse, H. (2016). Sobre Marx y Heidegger. Escritos Filosóficos (1932-1933). Biblioteca Nueva.

Marx, K. (1974). La Ideología Alemana. Grijalbo.

Marx, K. (2003). Manuscritos de Economía y Filosofía. Alianza Editorial.

Marx, K. (2008). El Capital: Crítica de la Economía Política. Vol. I. Tomo I. Siglo XXI Editores.

Marx, K. (2010). Marx \& Engels Collected Works. Vol. 1. Lawrence \& Wishart.

Marx, K. \& Engels, F. (1971). La Sagrada Familia o crítica de la crítica crítica. Editorial Claridad.

Marx, K. \& Engels, F. (1973). Cartas sobre las ciencias de la naturaleza y las matemáticas. Anagrama.

Merleau-Ponty, M. (1964). Marxism and Philosophy. En M. Merleau-Ponty, Sense and Non-sense (pp. 125-138). Northwestern University Press.

Schmidt, A. (1977). El concepto de naturaleza en Marx. Siglo XXI Editores.

Searle, J. (1997). La construcción de la realidad social. Paidós. 
Spinoza, B. (1980). Ética demostrada según el orden geométrico. Ediciones Orbis.

Stanley, J. L. (1998). Marx's Critique of Hegel's Philosophy of Nature. Science \& Society, 61(4), 449-473.

Stroud, B. (1996). The Charm of Naturalism. Proceedings and Addresses of the American Philosophical Association, 70(2), 43-55.

Wood, A. (2004). Karl Marx. Routledge. 